\title{
LANDMARKS EVALUATION WITH USE OF QR-CODE FOR POSITIONING INDOOR ENVIRONMENT
}

\author{
Amanda Pereira Antunes ${ }^{1}$ - ORCID: 0000-0001-9458-1368 \\ Luciene Stamato Delazari ${ }^{1}$ - ORCID: 0000-0003-0018-085X \\ ${ }^{1}$ Universidade Federal do Paraná, Departamento de Geomática, Curitiba, Paraná, Brasil. \\ E-mail: amandapereiraantunes@gmail.com, luciene@ufpr.br
}

Received on $12^{\text {th }}$ August 2019

Accepted on $17^{\text {th }}$ September 2019

\begin{abstract}
:
People tend to lose their sense of direction in closed environments and the role of indoor maps is to assist the user in navigating in these spaces, through understanding the environment, identifying reference points or positioning. Among the several forms of achieving positioning in indoor environments, this research used the method based on image recognition through identification of QR-Code labels, because of their low cost, easy implementation, and because their accuracy is not affected by the environment. As such, this article presents the use of QR-Code markers affixed to possible reference points to determine user positioning in an indoor environment using a mobile device. This study seeks to discover which are the most appropriate sites for placing QR-Codes in an environment, by evaluating what reference points and what type thereof are most used in indoor environments. This study is therefore based on the hypothesis that if initial positioning is obtained only through reference points this is sufficient for users to orient themselves. Through analysis of the results obtained from navigation tasks done by users we were able to obtain data regarding elements most cited as references. The results show that people orient themselves in distinct ways in the same environment and use as their main reference points structural elements of the environment such as stairways, lifts, and decision-making points; in general structural reference points were those most used to support orientation and navigation.
\end{abstract}

Keywords: Reference points; QR-Code; indoor environment

How to cite this article: ANTUNES, A. P.; DELAZARI, L. S. Landmarks evaluation with use of QR-code for positioning indoor environment. Bulletin of Geodetic Sciences. 25(4): e2019024, 2019. 


\section{Introduction}

Increasingly, navigation systems intended for indoor spaces are being used thanks to progress with mobile computing and communication via internet. Greater public use of spatial information generates new applications, boosts the demand for indoor representations and tools to use them (Zlatanova et al. 2013).

Indoor navigation systems are designed to assist users, as people tend to lose their sense of direction more easily inside buildings than outdoors (Huang et al. 2009). Use of navigation systems in indoor environments can significantly assist people in navigating in complex environments, since they can reduce the cognitive load used in orientation because they assist acquisition of knowledge about the environment (Ryder 2015). The task of exploring unknown areas becomes more efficient when relevant information on user positioning is shown than when no such information is available (Pombinho, Afonso, and Carmo 2011). Presenting information such as reference points also minimizes the cognitive effort that is linked to the need for orientation, planning, and monitoring of routes (Golledge 2004).

Reference points are prominent elements in the environment and enable users to locate themselves as well as to code spatial relationships between objects and routes. They can also be used as an orientation and navigation tool, since they serve as decision-making points and help to identify starting points and destination points (Sorrows and Hirtle 1999). Basiri, Amirian, and Winstanley (2014) state that the use of reference points in positioning systems provides benefits for users, as they assist navigation, can add information about important characteristics of places and enable users to check whether they are on the right route.

As in our research, Oliveira (2014), Ning (2013), Chang et al. (2007) and Basiri, Amirian, and Winstanley (2014), developed applications in their studies based on the positioning method using QR-Codes to analyze images. The mobile device camera captures the QR-Code, which is decoded by the system, which then presents a map of the place and the user's position. However, the tests performed in these studies were aimed at system functionalities; only Chang et al. (2007) tested application performance, through tests carried out with users, in which only $4 \%$ showed some amount of route deviation when following a route using the system developed. Through tests with users, the focus of our study is to discover which places are most appropriate for placing QR-Codes in an environment, since different approaches have been used with regard to sites where labels have been placed. For instance, in Oliveira's (2014) study, labels were placed in all rooms and exits; in Ning's (2013) study, labels were placed in some rooms, lifts, stairways, and entrances; in the study conducted by Chang et al. (2007) labels were also placed on doors and crossing points. None of these studies, however, explained what criteria were used to select these points. Only Basiri, Amirian, and Winstanley (2014) state that they used environment reference points for label placing and placed them on statues, historic monuments, library, and main entrances. Even so, the authors do not justify how these points were chosen or the reason why they were considered to be reference points.

Despite studies such as those of Vinson (1999) and Sorrows and Hirtle (1999) presenting characteristics that turn objects into points of reference, there is still lack of knowledge about what are reference points in effect indoor environment.

Sorrows and Hirtle (1999) states that reference points are fundamental for users being able to navigate in an environment since these elements help users to understand it. A unified definition regarding reference points helps to provide a means of evaluating these points and environments, apart from strengthening design decisions.

In order to propose a unified definition regarding reference points and understand what aspects turn an environment into a reference, Sorrows and Hirtle (1999) analyzed characteristics such as singularity or sharp contrast with the surroundings, prominence of location and accessibility, and the meaning of the place. These characteristics are important, since singularity in physical environments includes the distinction between a location and its immediate surroundings due to difference in size, shape, or position, while prominence, and accessibility are related to the fact of the location being visible from several other locations or a distance, or whether it can be reached by several different routes. An element in an environment can also be a reference depending on its content, meaning, use, or cultural meaning. 
Based on analysis of these characteristics, Sorrows and Hirtle (1999) proposes three categories of reference points:

Visual: They have characteristics that contrast with the environment, prominent spatial location, and visual characteristics that make the element particularly memorable. Examples include a cash machine; a library; signs; an entrance hall; doors.

Cognitive: Meaning stands out for being typical or atypical in the environment. For example, laboratories and secretaries' offices, despite appearing to be similar to other elements, such as classrooms, stand out owing to their meaning.

Structural: Their importance arises owing to their role, location, or structure in the environment. This class of reference points can be highly accessible and have a prominent location in the environment. For example, a footbridge joining two buildings would be a structural reference point; such as a library, a stairway, and a lift.

Some places might fit into more than one category owing to their characteristics. For example, a library has visual characteristics because it contrasts with the environment and structural characteristics due to its importance. Visual, cognitive, and structural categories of reference points appear to appropriately encompass all different types reference points in real spaces. Understanding each of these types of reference points will contribute to understanding how landmarks can be used and where they exist naturally (Sorrows and Hirtle 1999).

As such, our study is based on the hypothesis that if a user scans of QR-Codes only in places considered to be reference points, by using the indoor positioning system developed, the user will then be able to carry out orientation and navigation tasks based on the Information showing the user's location. However, the need exists to understand which places are considered to be reference points and which are used by a user during navigation. It is also of fundamental importance to understand to which categories reference points most used by users belong so that this information can support decision-making regarding placement of labels in projects or similar applications.

\section{Methods}

The methods used in this study (Figure 1) are divided into four main stages: cartographic representation, QRCode creation, positioning system development and tests with users. The first stage begins with the data evaluation to represent the area, the database modeling, data collection and classification, and generation of the schematic diagram. The second stage, involving QR-Codes, begins by analyzing possible reference points where labels can be placed, selecting placement points, generating and placing the labels. The third stage, regarding the positioning system, consists of generating the interface, generating linkage between each label and the map, and storing information. The final stage refers to tests, task definition, carrying out the tasks, and analyzing the results

The tests were carried out in the Institutes of Exact Sciences and Technology (IET) building and the Administration (ADM) building at the Federal University of Paraná (UFPR) Polytechnic Center campus. This environment was defined as the study area because of the heavy daily circulation of students and visitors. The buildings also have a variety of environments that can be analyzed as reference points, such as: classrooms and study rooms, teaching laboratories, common areas, commercial establishments, secretaries' offices, auditoriums, and WCs. Other factors influencing the choice of this area are related to user orientation difficulty inside the buildings, which may be caused by the complexity of the environment since the structural divisions of the blocks are similar and this causes confusion. Furthermore, as the buildings have several floors, this can cause loss of sense of direction, as well as the lack of signs, or out-of-date signs, which can result in mistakes during navigation. 


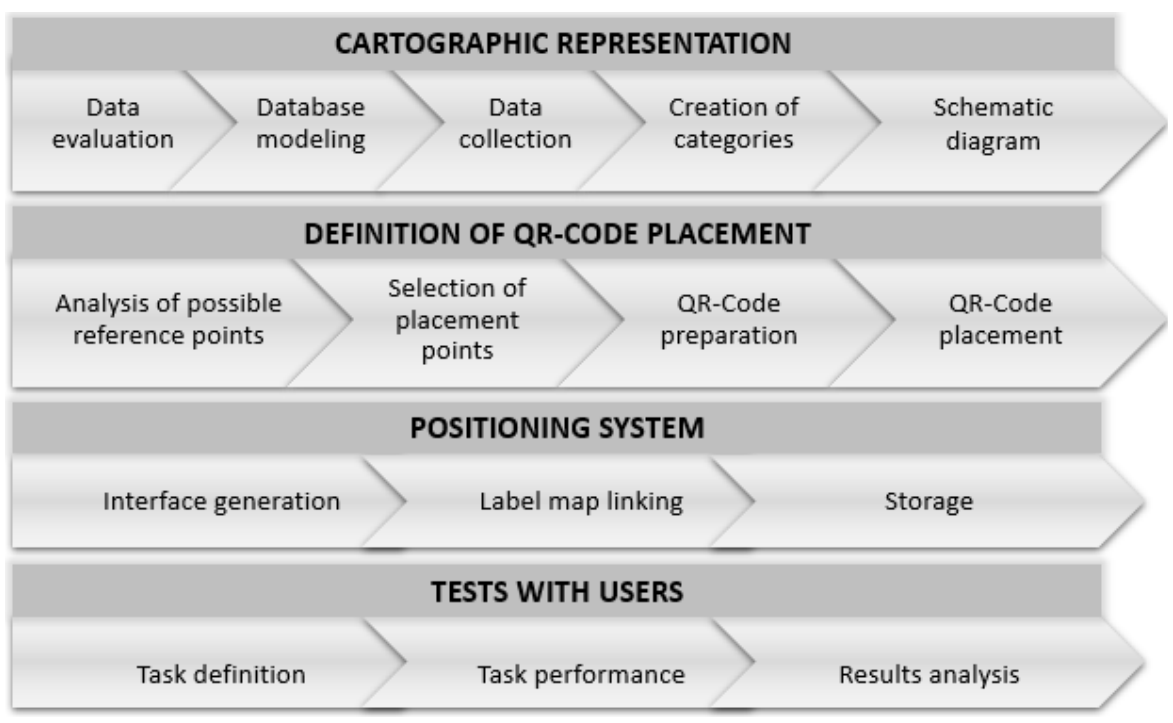

Figure 1: Stages of the study's methods.

Source: the author (2018).

\subsection{Cartographic Representation Design}

\section{The cartographic representation was prepared in five stages:}

Stage 1 - Evaluation of data needed to create a representation of the indoor environment: in order to check which data was available, the building plans of the study area were analyzed. Figure 2 shows a class diagram of spatial data generated using Astah software, containing all the information detected in the environment that enabled to represent the cartographic features of the study area. The OMT-G standard (Object Modeling Technique for Geographic Applications) was used to create the diagrams, which is based on the primitives defined for the UML (Unified Modeling Language) class diagram and introduces geographic primitives to increase the model's semantic representation capacity.

Stage 2 - Database modeling was performed to encompass the elements found in the previous stage and the database was implemented using PostgreSQL and its extension PostGIS. Under this proposal the database must contain the spatial information relating to the polygons that represent the internal areas of the study area, apart from non-spatial information, such as the name of an environment and its type or functionality. Information about floor of the building on which environments are located was also stored, this information is used by system, allowing the visualization of the environments of each floor separately. The building's geometry is taken to be the most relevant. In the context of spatial relationships, the building's geometry contains the geometry relating to the blocks, rooms, transition points, and corridors. The database contains two main tables, namely rooms, and transition points. The rooms table holds information relating to classrooms, laboratory, WCs, teachers' room, secretaries' offices, and other environments. The transition points table contains geometry representing doors, stairways, lifts, and exits.

Stage 3 - Field data collection was needed in order to update the data obtained from the building plans, owing to structural and functional modifications that had taken place over the years.

Stage 4 - Data collection led to 499 elements being mapped, such as: classroom, laboratory, secretaries' office, auditorium, library, WC, pantry, student union, study room, winter garden, depository, canteen, stationery store, storage room, junior enterprise, university extension, institute, workshop, training center, among others. The elements were grouped into 15 categories. The 'classroom, laboratory, secretaries' office, teachers' room, female WC, male WC, and disabled persons' WC" categories were created because of the large number of objects 
comprising them. The "library, auditorium, stationery store, and canteen" categories were created because they are unique elements that contrast with the environment. The "stairway, lift, and exit" categories were created because they are elements that stand out in the environment. The "other" category encompasses all the features that did not fit into any of the other categories mentioned, such as kitchen, storage room, and workshop.

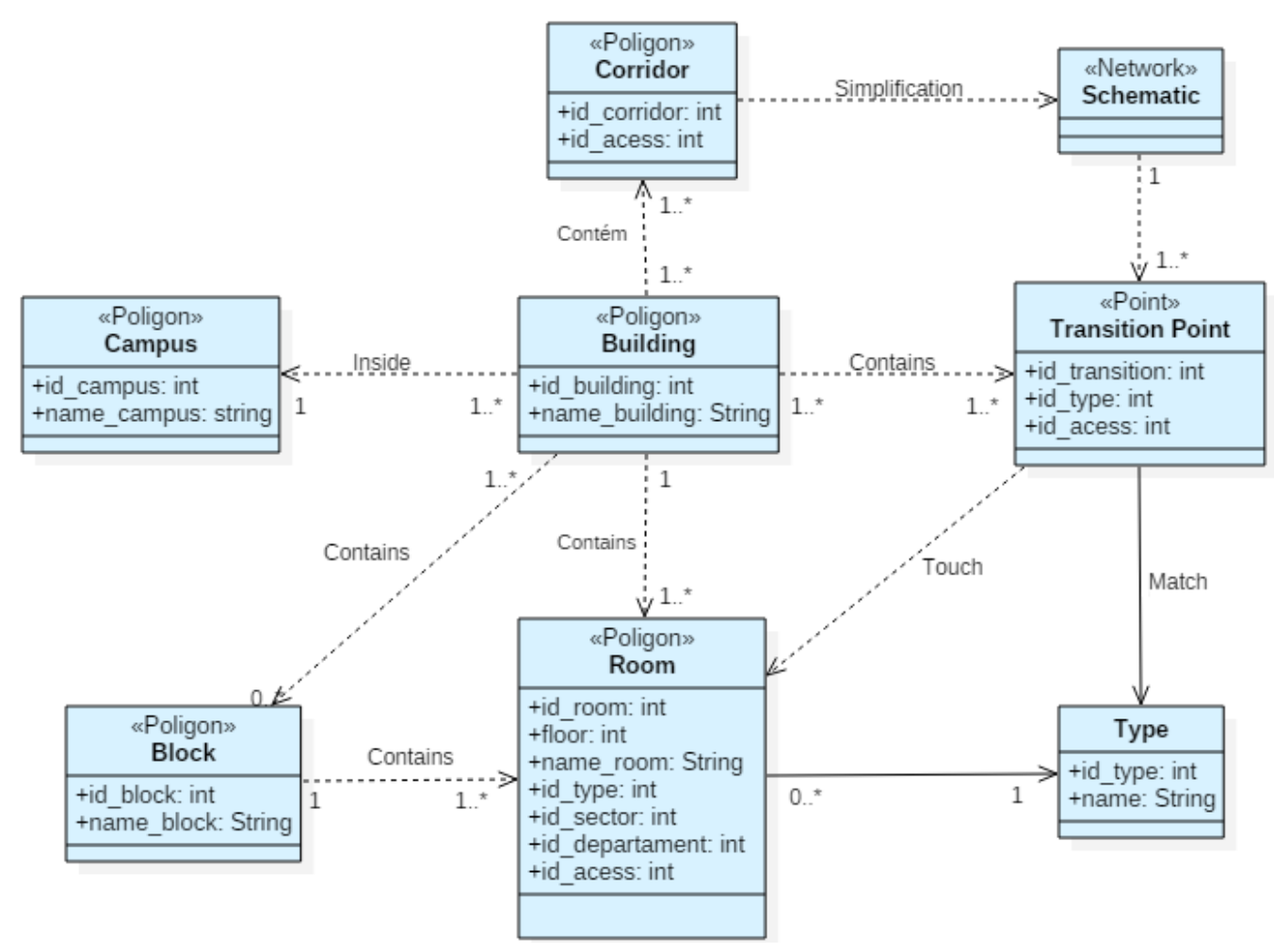

Figure 2: Class diagram.

Source: the author (2018).

Stage 5 - When generating the maps we opted for schematic diagrams due to their inherent simplicity and symbolic meaning, besides being more user-friendly than conventional maps (Avelar 2002). Even users who have difficulty in performing navigation tasks prefer to use schematic maps since representation of corridors using lines facilitates understanding of the indoor environment (Sarot and Delazari 2018).

\subsection{QR-Codes}

Our analysis of possible reference points was based on research by Sarot and Delazari (2018) in the same study area, in which users indicated which places they most used as a reference when moving around the environment, namely: stairways, WCs, commercial establishments, classrooms, and laboratories. All these places are represented in Figure 3, along with the places where the labels were affixed.

Following analysis of the layout of these elements, 58 points were selected for placing the labels. The criterion for choosing these points for the labels was based on those elements with greater contrast and prominence in relation to their surroundings. In the IET building the labels were placed separately in at least three reference points per corridor of the main block. In the Administration building the location of the reference points on each floor was similar. A label distribution pattern therefore emerges, since if there was a label near to the WC on one floor, for instance, there would also be one on the next floor near to the WC. A field visit was carried out to assess whether 
there was any kind of obstruction or element that could prevent the user from seeing or identifying the labels in these places. Figure 4 shows a pillar that could cause concealment and a notice board with an excessive amount of information which would hinder identification of a label if it were affixed nearby.
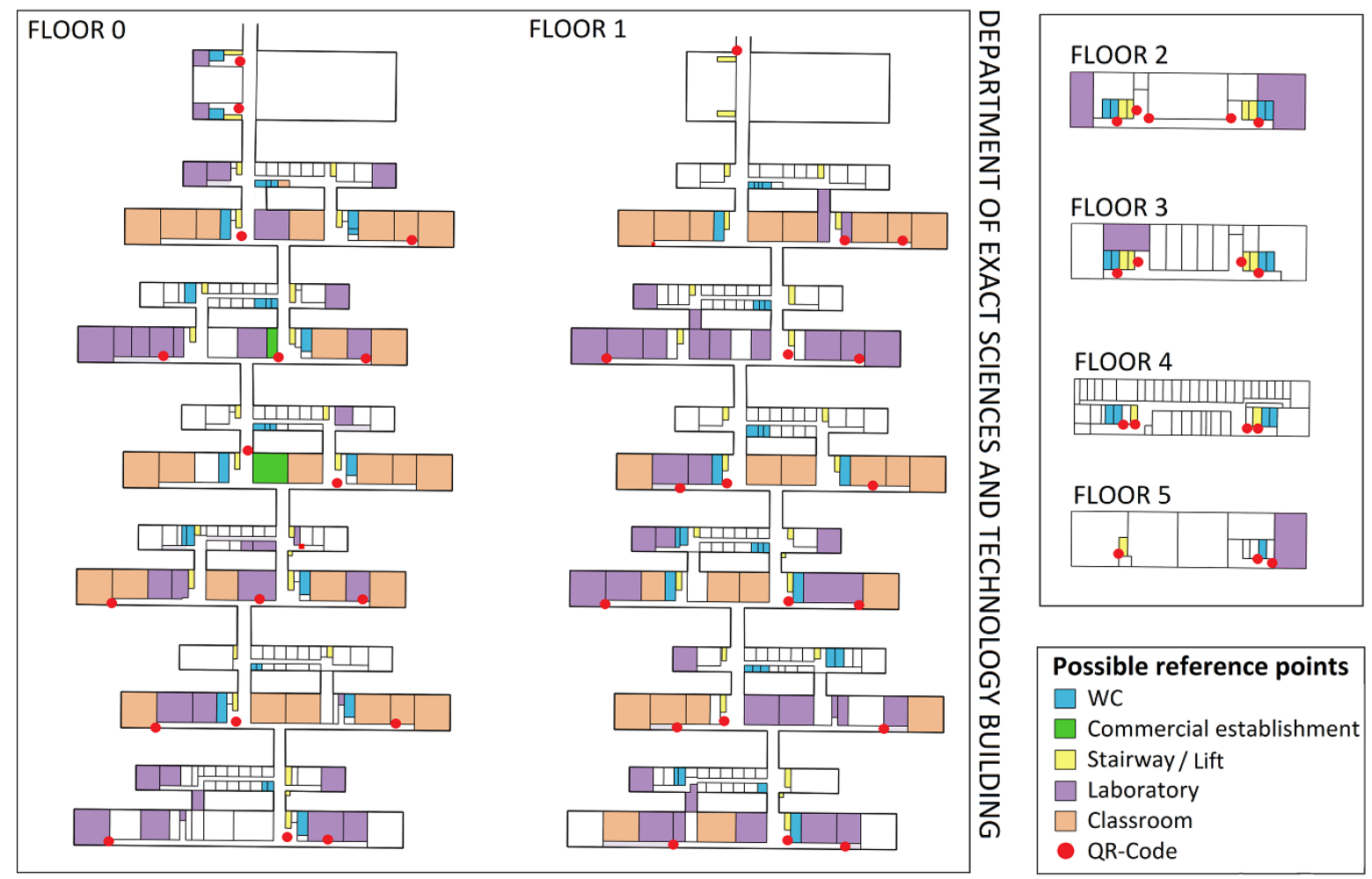

Figure 3: Possible reference points and labels.

Source: the author (2018).

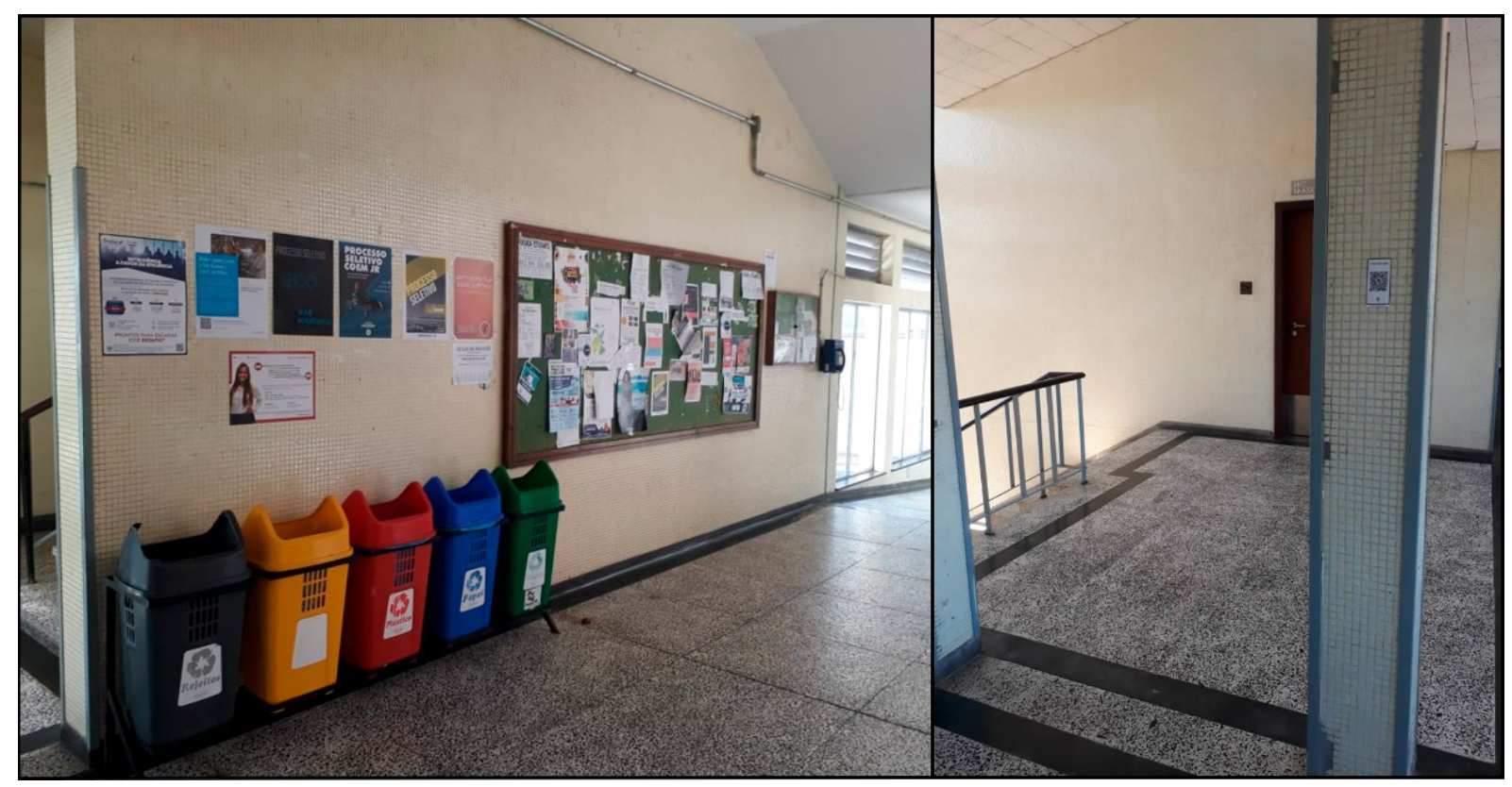

Figure 4: Obstructions.

Source: the author (2018). 
The QR-Codes were created using the Unitag QR label generator and scanner, available at https://www.unitag. io/qrcode, a free-of-charge online generator chosen for being easy to use, availability of different label formats and for allowing customization, such as inserting an image over the QR-Code. A marker symbol was chosen for QRCode customization (Figure 5), with the aim of making labels more user-friendly with regard to their functionality. According to Lin (2015), information can be transmitted when an image is incorporated into a QR-Code. For instance, when a company's logo is inserted, characteristics of the code's owner are transmitted to the user. Moreover, use of images in QR-Codes highlights the label and draws the viewer's attention.

Unitag QR creates labels with a rectangular frame in order to draw attention to the labels without necessarily enlarging the QR-Code. The frames measure $10 \mathrm{~cm} \times 6 \mathrm{~cm}$. The labels were affixed $1.65 \mathrm{~m}$ from the ground in order to be approximately on a level with the participants' line of sight. The labels were printed and affixed in the selected places using adhesive tape. Each QR-code generated is linked to a reference point. This enables the connection between the real world and the positioning system by showing the user's location on the map with a red arrow, as shown in Figure 5.

\subsection{Indoor Positioning system}

A web interface was developed to enable the map to be viewed on a Samsung GalaxyTab4 Tablet (Figure 5). After the first access, it works without relying on internet access, with the aim of minimizing problems related to lack of internet access. The purpose of the interface is to show the map of the environment and the user's position. It also enables each floor of the building to be viewed separately. Moreover, by clicking on a feature information about it is shown.

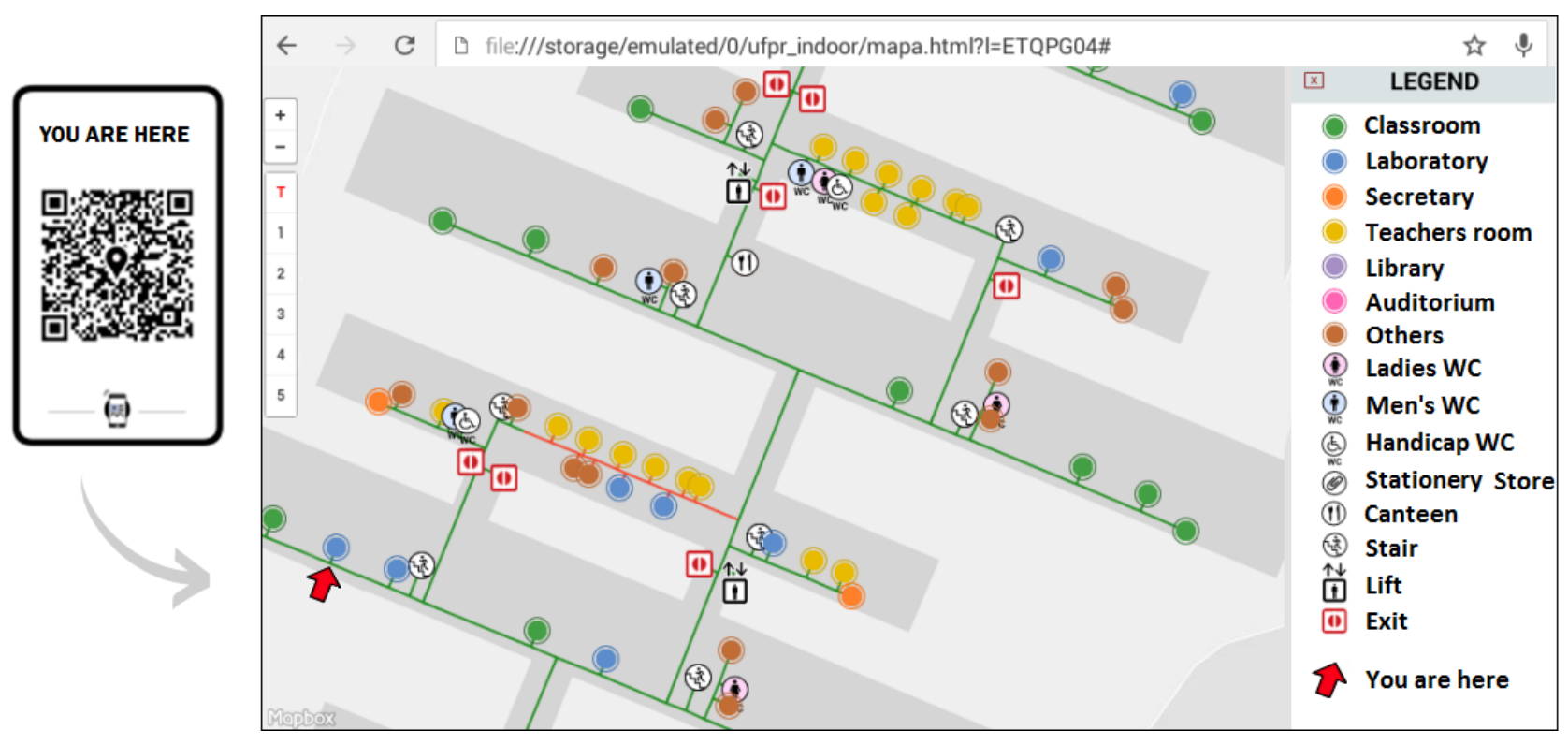

Figure 5: Interface.

Source: the author (2018).

The indoor positioning system was created with the aid of the Mapbox.js application which enables maps to be published on a webpage, showing information stored on the database via the PostgreSQL database management system. The link between the database and Mapbox.js was done using the Thormap application, which was developed using the PHP and Javascript programming languages at the UFPR Cartography Laboratory. Figure 6 shows the system function scheme starting with a QR-Code label being read. Following this the map is requested via the client device. 


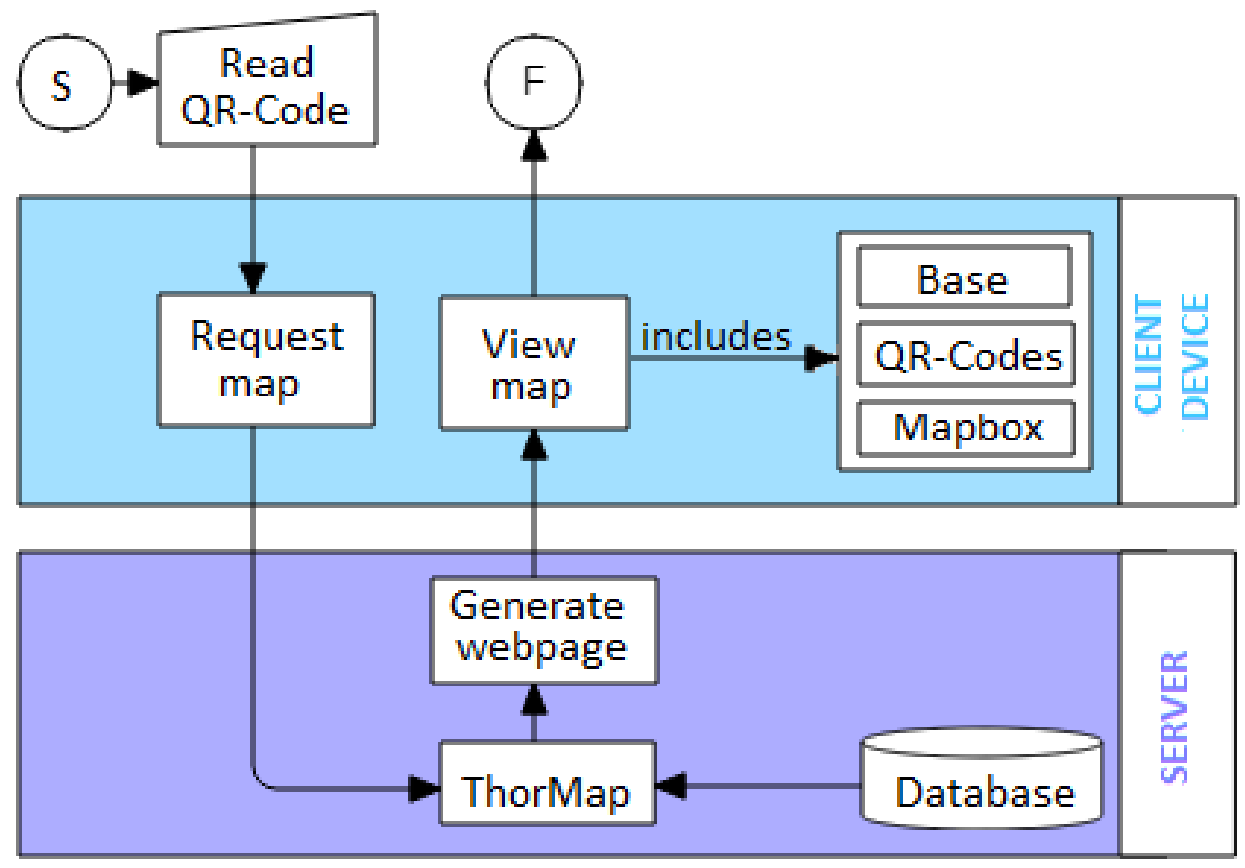

Figure 6: System operation.

Source: the author (2018).

A map service is generated on the server by Thormap. It uses PostGIS with the aim of retrieving spatial data from the database, along with their graphic definitions, such as line thickness and colour. Thormap transforms the data into a notation that can be used by the indoor positioning system created, thus enabling the map to be shown on the client device. Integration between the basic data, Mapbox and the QR-Codes enables the final map and the user's position to be shown on the screen.

\subsection{Tests with users}

Thirty participants carried out the tests involved in this study. They were all UFPR students selected because they knew the study area and could thus add more information regarding identifying and finding the environment's reference points. The participants were divided into two groups of 15 participants: the first group used QR-Code labels to find their position, while the second group had no help other than the map. The participants were divided into two groups in order to enable comparisons between the responses obtained via the navigation tasks carried out.

\subsubsection{Tasks}

In all six tasks (Figure 7) were done with the participants. The objective of tasks 1, 3, 5, and 6 was to obtain information about reference points that was used and taken into consideration by the participants inside the environment. It is then possible to filter information that is used the most and determine the types thereof. Tasks 2 and 4 are analyses relating to the time it takes the groups to complete a route. Group 1 is supported by the indoor positioning system indoor while Group 2 is not. The result of the tasks enables assessment of whether the system is efficient by using QR-Codes only at the reference points. 


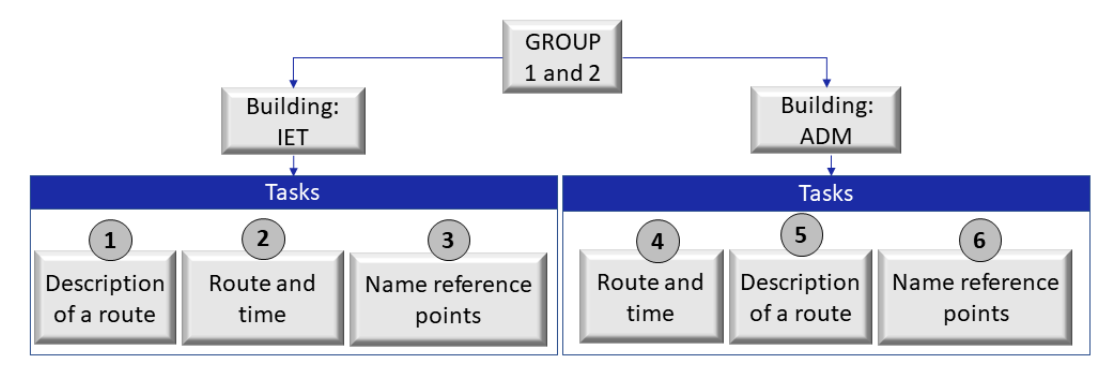

Figure 7: Tasks.

Source: the author (2018).

The first task (Figure 8) consisted of doing a route and at the end of it participants had to explain the route taken as if they were explaining it to someone who did not know the place and who needed to go from one point to another. Taking this description it is possible to analyze reference points they mention and note along the way. On this route there are laboratories, classrooms, teacher's rooms, WCs, stairways, and a lift, among other elements. Only two points were chosen for doing the route, namely a starting point and a finishing point in order to make it a simple and memorable route.

In the second task (Figure 8) participants had to take the route they thought easiest to find four predetermined places. Four points were chosen in order to generate greater complexity along the route, since the choice of the points was made in such a way that users needed to change floors and walk in the opposite direction to that taken when they began the route. This task was created to test how long users took to do it, with and without the aid of positioning labels. The purpose of this task is to analyze the use of labels as a means of obtaining positioning and the difficulties encountered by users, analyzing whether users felt the need to use labels along the route and whether they found the labels easily in the environment.
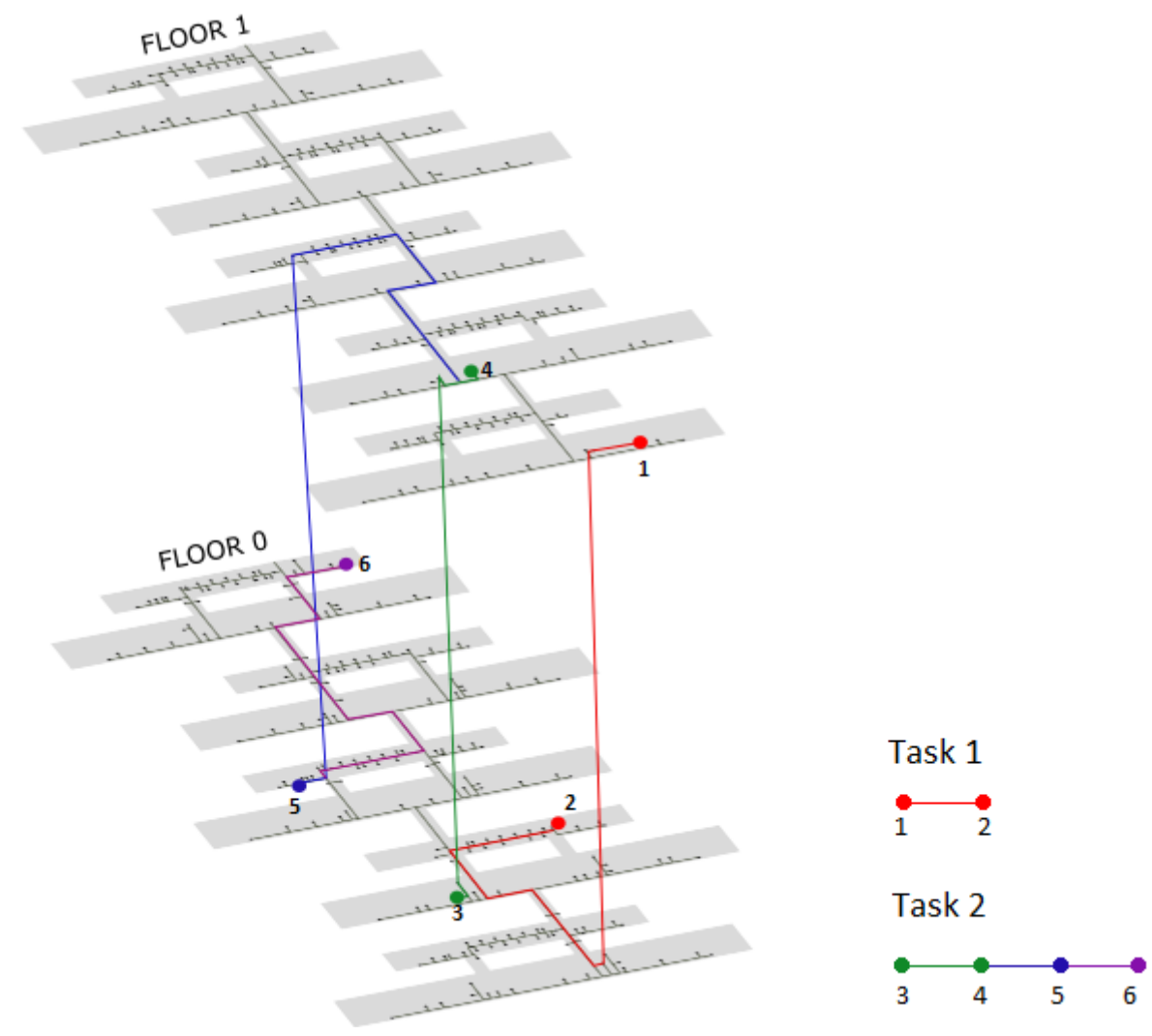

Figure 8: Tasks 1 and 2.

Source: the author (2018). 
In the third task the users were asked directly, without receiving options or suggestions, which points they considered to be reference points in the IET building. Through this question it can check whether the possible reference points proposed in this study are in keeping with the answers.

Tasks 4, 5, and 6 were performed in the Administration building. Task 4 consisted of evaluating how long users took to complete a route between two points, leaving the third floor and going to the Graphic Expression Department Secretary on the fifth floor, and whether they felt disorientated and needed to use the system to reposition themselves (Figure 9).

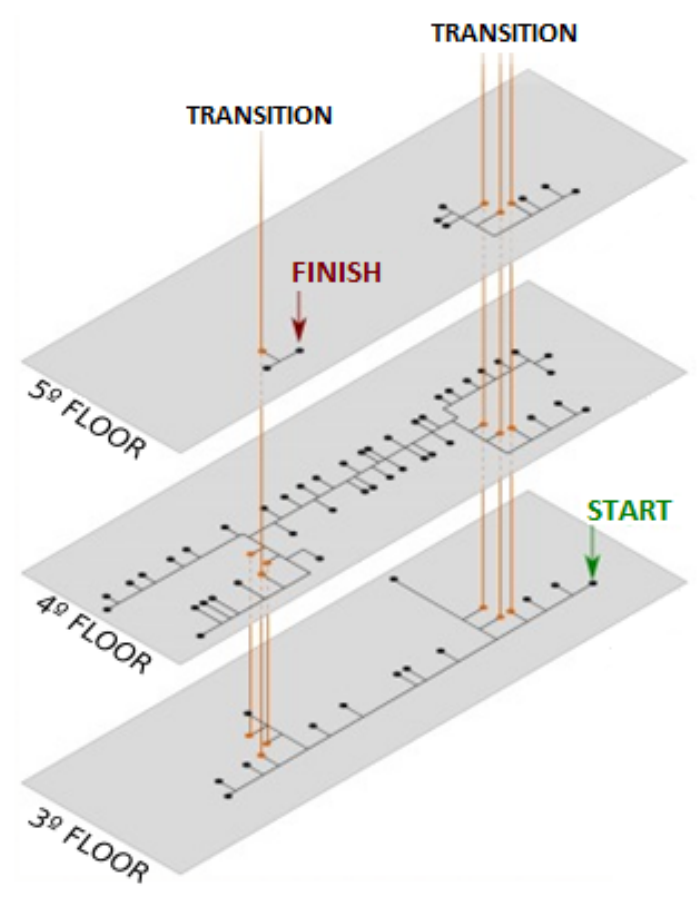

Figure 9: Task 4.

Source: Farias and Delazari (2017).

The fifth task consisted of describing the route taken in the previous task. Through this description the elements named in the environment can be identified. In task 6 the participants had to name what they considered to be reference points in the Administration building.

\section{Result evaluation}

The tests were carried out with 30 participants, of whom 16 were female and 14 were male, with eight females and seven males in each group. The majority of the participants (18) were in the 21-30 age range and 13 had university degrees. Although they have prior knowledge about study area, $90 \%$ of participants are not confident about teaching a route to someone, as they visit only specific rooms and do not know the entire building.

All the analyses are done by group, whereby group 1 used QR-Codes for positioning while group 2 was only aided by the map. With regard to the first task, the following reference points (Figure 10) were extracted from the descriptions of the routes taken by the participants. 


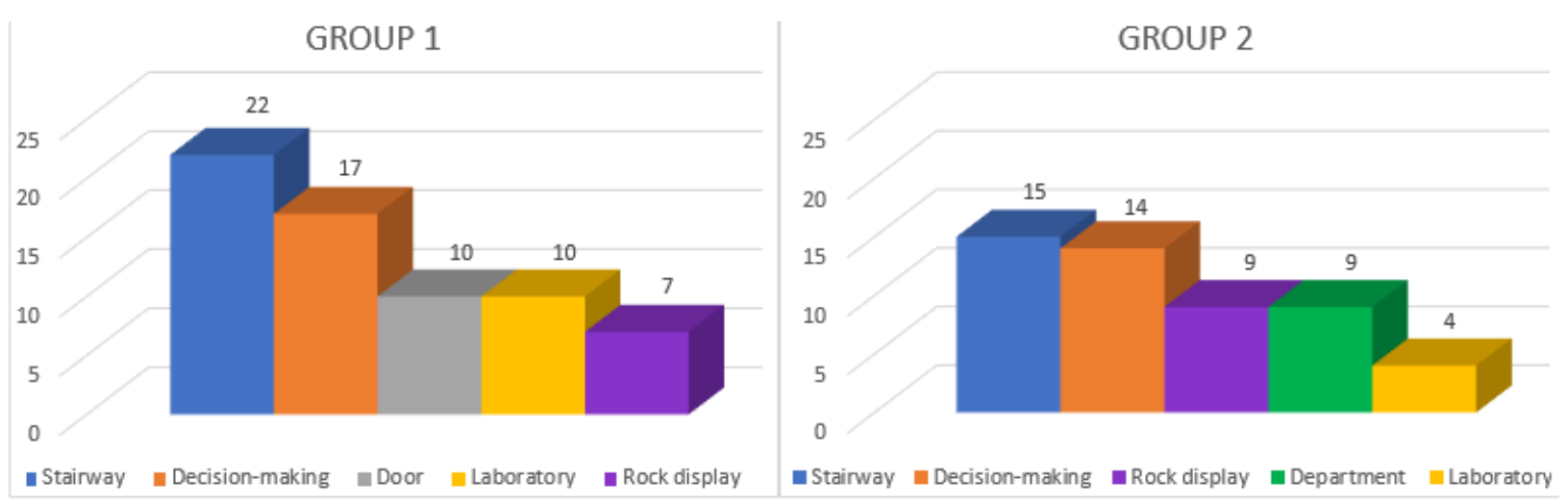

Figure 10: Task 1 - Reference points.

Source: the author (2018).

The elements most mentioned as reference points by both groups were: stairway and decision-making points such as T-shaped intersections in the corridors, which according to Sorrows and Hirtle' (1999) classification are structural reference points; department, laboratory, which are cognitive reference points; and rock display and doors, which are visual reference points.

In the second task participants had to take the route they thought easiest to find the four predetermined places. All participants of both groups managed to complete the task, although group 1 (which used positioning labels) completed it more quickly, taking 10.06 minutes on average. Average time taken by group 2 was 11.4 minutes.

In the third task the users were asked directly, without receiving options or suggestions, as to which points they considered to be reference points in the IET building. Table 1 shows the results.

Table 1: Task 3 - Reference points.

\begin{tabular}{c|c|c|c}
\hline GROUP 1 & QUANTITY & GROUP 2 & QUANTITY \\
\hline Canteen & 11 & Library & 7 \\
\hline Library & 4 & Canteen & 7 \\
\hline Stationery store & 4 & Stationery store & 3 \\
\hline WC & 3 & Stairway & 3 \\
\hline Decision-making & 3 & Sign & \\
\hline
\end{tabular}

According to the reference point classification given by Sorrows and Hirtle (1999), the elements most mentioned by the two groups were: sign, which is a visual reference point; WC is a cognitive reference point; library, canteen, and stationery store, are structural and visual reference points, while stairway and decision-making points are structural reference points.

Task 4 consisted of evaluating the time taken by the user to leave the third floor of the Administration building and go the Graphic Expression Secretary's office on the fifth floor. Group 1, which used QR-Code labels, took 3.53 minutes on average, while Group 2 took 5.35 minutes on average, there thus being a difference of 2 minutes between the groups.

The fifth task consisted of describing the route taken in task 4 . As a result the following reference points shown in Table 2 were obtained.

The elements most named by both groups were: door, which is a visual reference point; WC and secretaries' office are considered to be cognitive reference points; and finally, lift, stairway, and decision-making points are structural reference points. 
In task 6 participants were asked to name what they considered to be reference points in the Administration building. The most mentioned elements (Table 3) by the two groups in the two tasks were stairway and lift, which are structural reference points. Hall is a visual reference point and auditorium is cognitive.

In this task some participants stated that there is no reference point standing out or which is memorable in this building, despite having used elements of the environment to describe the route. In tasks 5 and 6 , which were performed in the Administration building that has five floors, it can be seen that the lift is indicated as a point of reference, while in tasks 1 and 3, performed in a building that only has two floors, the lift is not mentioned as a reference. When analyzing the answers obtained for all the tasks it was possible to determine which reference points were most used by each group (Table 4).

Table 2: Task 5 - Reference points.

\begin{tabular}{c|c|c|c}
\hline GROUP 1 & QUANTITY & GROUP 2 & QUANTITY \\
\hline Stairway & 12 & Stairway & 18 \\
\hline Lift & 7 & Lift & 3 \\
\hline WC & 2 & Secretaries' office & 2 \\
\hline Doors & 2 & Decision-making & 2 \\
\hline
\end{tabular}

Table 3: Task 6-Reference points.

\begin{tabular}{c|c|c|c}
\hline GROUP 1 & QUANTITY & GROUP 2 & QUANTITY \\
\hline Lift & 10 & Stairway & 4 \\
\hline Stairway & 7 & Hall & 4 \\
\hline Hall & 2 & None & 3 \\
\hline None & 2 & Auditorium & 2 \\
\hline
\end{tabular}

Table 4: Reference points.

\begin{tabular}{c|c|c|c|c|c|c|c|c|c|c}
\hline & \multicolumn{4}{|c|}{ GROUP 1 } & \multicolumn{3}{c|}{ GROUP 2 } & \multicolumn{3}{c}{ TOTAL } \\
\hline Point of reference & T1 & T3 & T5 & T6 & T1 & T3 & T5 & T6 & GROUP 1 & GROUP 2 \\
\hline Stairway & 22 & & 12 & 7 & 15 & 3 & 18 & 4 & 41 & 40 \\
\hline Decision-making & 17 & 7 & & & 14 & & 2 & & 24 & 16 \\
\hline Door & 10 & & 2 & & & & & & 12 & 0 \\
\hline Laboratory & 10 & & & & 4 & & & & 10 & 4 \\
\hline Rocks & 7 & & & & 9 & & & & 7 & 9 \\
\hline Department & & & & & 9 & & & & 0 & 9 \\
\hline Canteen & & 11 & & & & 7 & & & 11 & 7 \\
\hline Library & & 4 & & & & 7 & & & 4 & 7 \\
\hline Stationery store & & 4 & & & & 5 & & & 4 & 5 \\
\hline WC & & 3 & 2 & & & & & & 5 & 0 \\
\hline Sign & & & & & & 3 & & & 0 & 3 \\
\hline Lift & & & 7 & 10 & & & 3 & & 17 & 3 \\
\hline Secretaries' office & & & & & & & 2 & & 0 & 2 \\
\hline Hall & & & & 2 & & & & 4 & 2 & 4 \\
\hline Auditorium & & & & & & & & 2 & 0 & 2 \\
\hline
\end{tabular}


Based on the results shown in Table 4, Figure 11 was generated showing the elements most mentioned by group 1 which used the QR-Codes, the percentage and the category to which each element belongs. Figure 11 also shows the same information, but in relation to group 2 which did not use the labels.
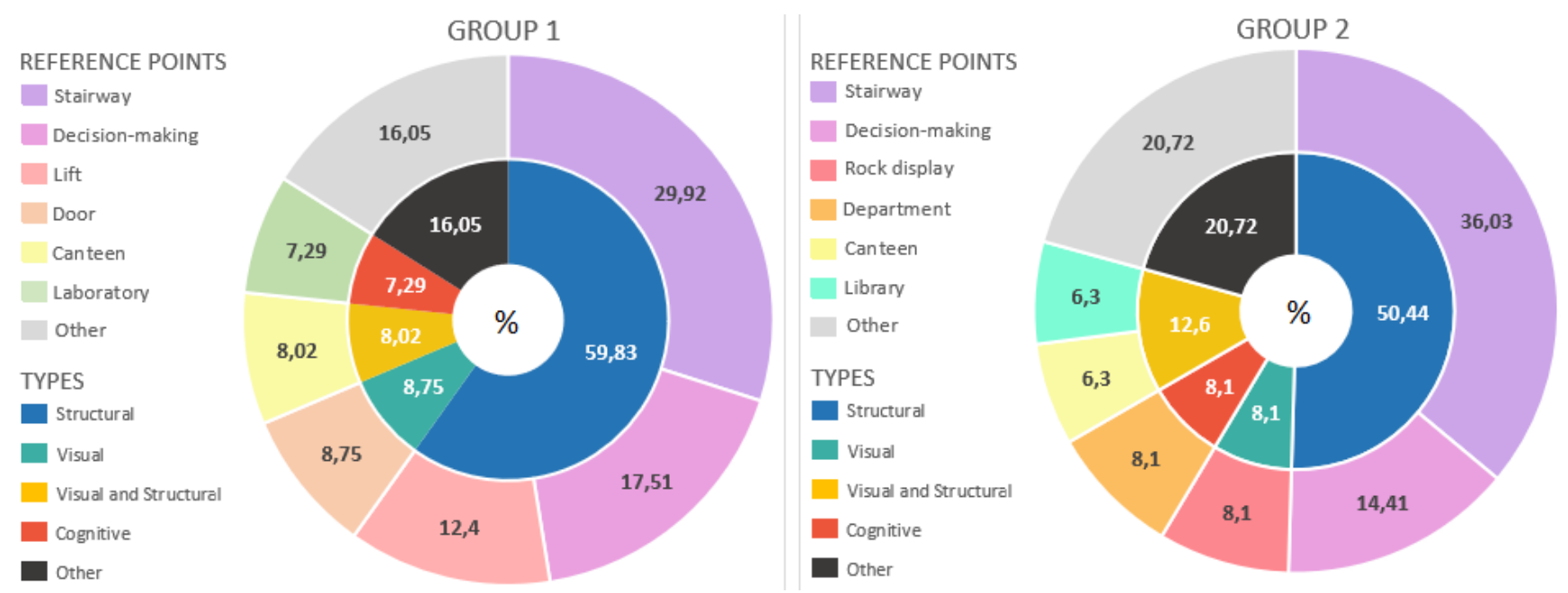

Figure 11: Reference points - Group 1 and 2.

Source: the author (2018).

Based on the results shown in Figure 11 it was can conclude that the elements most used as a reference inside the environment are structural and visual elements, which either stand out because of their structure or draw attention visually because they contrast with the environment.

\section{Conclusion}

The use of labels to obtain positioning was found to be efficient, since in both tasks in which time taken was analyzed the group assisted by the labels did the tasks more quickly. The group that did not use labels was seen to have slightly more difficulty in determining its initial position and consequently took more time to complete the task.

Some participants used labels even when they were not lost or disorientated, to make sure they were where they thought they were. When they found that they were in the right place they felt more confident about continuing on the route. Participants who were not aided by the labels asked themselves if they were really where they thought they were and spent more time at that place attempting to relate the map to the environment in order to confirm their position. Therefore, positioning using QR-Code labels assists navigation, minimizes the time spent and generates a sensation of security and confidence in the user.

According to all group 1 participants, the amount of labels in the environment was sufficient, and as such the hypothesis of our study is confirmed. Therefore, if positioning is determined only by reference points, the user is able to carry out navigation and orientation tasks with few difficulties. It is suggested that future research evaluate elements such as format, type, and colour used in the representation of the QR-Code labels affixed, and whether these elements can facilitate identification by the user in the environment.

With regard to the reference points, the elements most mentioned by the participants of both groups are elements that stand out in the environment because of their structures, such as stairways, lifts, and decision-making points. As such, it was conclude that structural reference points are most used within an indoor environment to aid navigation and orientation and, therefore, they are the most indicated for affixing QR-Code labels. However, results 
achieved and conclusions drawn can only be expected in an environment similar to the test environment and to the participants' characteristics. Therefore, it is recommended to evaluate reference points in different environments and with participants who have more diverse characteristics, to verify whether if the structural reference points are also the most used.

Through this comparative analysis between the two buildings it was also possible to perceive that a building's architecture influences the determination of reference points. For example, in the environment that only has two floors, the lift is practically not mentioned as a reference, while in the environment with five floors the lift takes on significant importance for participant orientation.

\section{ACKNOWLEDGEMENT}

The authors would like to thank the Conselho Nacional de Desenvolvimento Cientifico e Tecnológico (CNPq) and Coordenação de Aperfeiçoamento de Pessoal de Nível Superior (CAPES) for their financial support (Process: 459300/2014-8 - Edital Universal; Process: 310312/2017-5 - Produtividade em Pesquisa).

\section{AUTHOR'S CONTRIBUTION}

Author Amanda Pereira Antunes designed the study, including the tests, data analysis, and writing. Author Luciene Stamato Delazari designed the study and writing.

\section{References}

Avelar, S. 2002. Schematic Maps on Demand: Design, Modeling and Visualization. PhD thesis, Swiss Federal Institute of Technology Zurich.

Basiri, A., Amirian, P. and Winstanley, A. 2014. The Use of Quick Response (QR) Codes in Landmark-Based Pedestrian Navigation. International Journal of Navigation and Observation, pp. 1-7.

Chang, Y. J., Tsai, S. K., Chang, Y. S. and Wang, T. Y. 2007. A Novel Wayfinding System Based on Geo-coded QR Codes for Individuals with Cognitive Impairments, 9th international ACM SIGACCESS conference on Computers and accessibility. Tempe, Arizona, USA, pp. 231-232.

Farias, P. P. S. and Delazari, L. S. 2017. Cálculo de rotas com o algoritmo do caminho mais curto em ambientes indoor. IV Simpósio Brasileiro de Geomática, Presidente Prudente -SP, pp. 65-70.

Golledge, R. G. 2004. Human Wayfinding, Applied Geography - A World Perspective, The GeoJournal Library. Volume 77. Chater 12. pp. 233-252.

Huang, H., Gartner, G., Schmidt, M. and Li, Y. 2009. Smart Environment for Ubiquitous Indoor Navigation, International Conference on New Trends in Information and Service Science, pp.176-180.

Lin, S. S., Hu, M. C., Lee, C. H. and Lee T. Y. 2015. Efficient QR Code Beautification With High Quality Visual Content. IEEE Transactions on Multimedia, Volume: 17, Issue: 9

Ning, A. J. 2013. QR-MAP: byod indoor map directory service. Dissertation Bachelor of Computer Science, University Tunku Abdul Rahman. Perak, Malasia. 
Oliveira, N. M. F. L. 2014. Localização indoor por identificação de marcos. Dissertação de mestrado em Engenharia Informática, Universidade do Minho, Escola de Engenharia.

Pombinho, P., Afonso, A. P. and Carmo, M. B. 2011. Point of Interest Awareness Using Indoor Positioning with a Mobile Phone. PECCS 2011, 1st International Conference on Pervasive and Embedded Computing and Communication Systems, Vilamoura, Algarve, Portugal, pp. 5-14.

Ryder, K. J. 2015. Designing and Publishing Indoor Maps for Patients and Visitors in an Academic Teaching Hospital, MSc thesis. Dublin: Royal College of Surgeons in Ireland.

Sarot, R. V. and Delazari, L. S. 2018. Evaluation of Mobile Device Indoor Maps for Orientation Tasks. Bulletin of Geodetic Sciences, Vol. 24 (4): pp. 564-584.

Sorrows, M. E. and Hirtle, S. C. 1999. The Nature of Landmarks for Real and Electronic Spaces, International Conference on Spatial Information Theory: Cognitive and Computational Foundations of Geographic Information Science, pp. 37-50.

Vinson, N. G. 1999. Design Guidelines for Landmarks to Support Navigation in Virtual Environments. SIGCHI Conference on Human Factors in Computing Systems. Pittsburgh, Pennsylvania, USA, pp. 278-285.

Zlatanova, S., Sithole, G., Nakagawa, M. and Zhu, Q. 2013. Problems In Indoor Mapping and Modelling. ISPRS International Archives of the Photogrammetry, Remote Sensing and Spatial Information Sciences, Cape Town, South Africa, pp. 63-68. 